\title{
Quality of life and severity of skin changes in the dynamics of psoriasis
}

\author{
Krzysztof Owczarek, Mariusz Jaworski \\ Department of Medical Psychology, Medical University of Warsaw, Warsaw, Poland
}

Adv Dermatol Allergol 2016; XXXIII (2): 102-108

DOI: 10.5114/pdia.2015.54873

\begin{abstract}
Introduction: Psoriasis is a chronic skin disease with periods of recurrence and remission. The skin changes which are typical of this disease can have a considerable effect on the patient's psychological state, self-esteem and body image. It can also affect the patient's functioning in all areas of life and quality of life.

Aim: The present study characterized the patient needs to improve the quality of life in specified areas in patients depending on the severity of psoriatic changes.

Material and methods: The study was conducted in two stages on 100 patients aged from 18 to 66 . A dermatological examination was conducted in stage one. Patients' dermatological condition was assessed with the Psoriasis Area and Severity Index (PASI). Clinical and socio-economic information was collected in stage two using a questionnaire, a medical interview and a standardized questionnaire measuring quality of life, the WHOQOL-BREF.

Results: The following factors had the greatest effect on the general quality of life and quality of health ratings in the studied sample: severity of psoriatic changes, duration of the most recent recurrence and sex. Severity of psoriatic changes had a negative effect on the patient's somatic, psychological, environmental and social functioning. Duration of the most recent recurrence had a negative effect on social functioning. Practical implications of this study allow dermatologists to determine the appropriate therapeutic intervention which improves the quality of life of these patients on the one hand, and will increase patient's involvement in the process of treatment on the other hand.
\end{abstract}

Conclusions: Quality of life is more impaired by more severe chronic skin disease.

Key words: quality of life, skin changes, PASI, psoriasis.

\section{Introduction}

Psoriasis is a chronic inflammatory skin disease. It has periods of recurrence and remission. If we review the literature we will find that several factors contribute to its development such as auto-immunological, genetic, hormonal and psychosomatic ones [1-3]. The condition is equally frequent in men and women and affects from $1.5 \%$ to $3 \%$ of the population [4]. It is diagnosed on the basis of observable skin changes and its treatment is one of the most difficult dermatological challenges. Psoriasis typically manifests as red scaly rashes and itching. Treatment is generally external (specific and nonspecific), general (including retinoids, immunomodulating and cytostatic drugs) and physical (including photochemotherapy, phototherapy, heliotherapy) $[1,5]$.

In the latest literature attention is drawn to the role of psychological factors in the frequency of recurrence and remission and treatment dynamics [5-7]. This is because the skin is important in human aesthetics and appearance. It is also an important factor in nonverbal communication and interpersonal relations, partly because it is involved in emotional expression. Therefore, chronic dermatological conditions have a significant effect on patients' psychological condition, self-esteem and body image. They also affect patients' functioning in all other spheres of life (social, family, professional etc.) and contribute fundamentally to quality of life [6, 8]. Awareness of the fact that one is ill and suffering has its important individual, subjective aspect. The range and content of experienced difficulties, restrictions on daily living and related anxieties are so heterogeneous and unique that we can confidently compare them, without fear of exaggeration, with the uniqueness of human fingerprints. Physicians often equate helping patients with optimization of pharmacotherapy and their basic

Address for correspondence: Mariusz Jaworski PhD, Department of Medical Psychology, Medical University of Warsaw, 81 A Żwirki i Wigury St, 02-091 Warsaw, Poland, phone: +48 783680 734, e-mail: mjaworski@wum.edu.pl Received: 1.12.2014, accepted: 2.02.2015. 
criterion of treatment effectiveness is the level of recovery in a strictly medical sense. Focus on the biological aspect of disease and clinical outcomes of drug treatment seriously limit doctor's thinking. Helping patients involves much more than that and includes improving the patient's psycho-social functioning and teaching the patient to find satisfaction in daily life. Or, more generally, the goal of contemporary therapy is to improve patients' health-related quality of life (HRQOL). The HRQOL assessment helps us to see how seriously the illness is interfering with normal functioning and affecting performance of social roles. It also helps us to see what is causing tension and stress in the patient. The HRQOL assessment helps us to determine the reasons for poor treatment effectiveness and find the most effective methods of treatment for a given patient. Finally, it has a number of tangible, economic benefits as well [9].

There are many studies highlighting the relationship between disease symptoms and quality of life in patients with psoriasis. Improving the quality of life is one of the main expectations of these patients associated with a visit to a dermatologist. Therefore, it requires special attention and systematically emphasizes the importance of this area in medical practice [1, 5, 6, 8, 10-14]. This is very important because realization of these needs may affect the patient's involvement in the process of treatment, adherence to medical recommendations and satisfaction with medical treatment [15]. Proper patient-doctor relationship is the main method of implementation of the discussed needs in contemporary medical practice, especially through the use of elements of a motivational interview.

\section{Aim}

The aim of the present study was to characterize specific areas of the quality of life which could deteriorate in patients depending on the severity of clinical parameters. There are studies which show that the doctors have difficulty in identifying the needs of the patient. In addition, this study allows to characterize the patient's needs to improve the quality of life in specified areas in patients depending on the severity of psoriatic changes.

Practical implications of this study allow dermatologists to determine the appropriate therapeutic intervention which improves the quality of life of these patients on the one hand, and will increase patient involvement in the process of treatment on the other hand. If the doctor determines the severity of psoriatic changes, he/she will get important knowledge concerning the needs and expectations of patients with respect to the proposed treatment as well as improvement of quality of life. Such activity of the doctor allows for an individual approach to the patient, and thus increases the effectiveness of the proposed treatment.
Four areas of quality of life were analysed in relation to the main objective. The present study was to assess somatic, psychological, social and environmental quality of life in patients with psoriasis depending on the severity of clinical parameters. We reviewed the literature and formulated the following research hypotheses:

- H1: Patients with severe psoriasis are characterized by a poorer subjective rating of general quality of life compared to mild psoriasis.

- H2: Patients with severe psoriasis are characterized by a poorer subjective rating of four aspects of life: psychological, physical, social and environmental compared to mild psoriasis.

- H3: Patients with severe psoriasis are characterized by a poorer subjective rating of perception of their own health compared to mild psoriasis.

\section{Material and methods}

The study was conducted on 100 patients with psoriasis (45 women and 55 men) aged from 18 to 66 (mean $=36.00 ; \mathrm{SD}=1.80$ ) who are treated in dermatological clinics in Warsaw. The subjects were recruited from patients who were: 1) over 18, 2) with diagnosed psoriasis, 3) subject to ongoing therapy, 4) and gave informed consent to be a part of the study. All patients gave informed consent. There were two stages. Patients were examined dermatologically in stage one and submitted to questionnaire testing in stage two. The purpose of stage one was to assess the severity of psoriatic skin changes using the Psoriasis Area and Severity Index (PASI). The PASI can range from 0 to 72 (where 0 - no severe symptoms and 72 - the most severe symptoms) [16]. Participants were divided into three groups according to their PASI scores following the recommendations of Schmitt and Wozel [17]: < 7-mild, 7-12 - moderate and > 12 - severe.

Stage two was a self-report stage involving a questionnaire and a medical interview. The following clinical and socio-demographic information was collected: 1) age, 2) sex, 3) age at first diagnosis of psoriasis (years of life), 4) currently used anti-psoriatic medication, 5) duration of the last clinical recurrence in months, and 6) duration of the last clinical remission in months. Patients were then asked to fill in a standardized questionnaire measuring quality of life, the WHOQOL-BREF. This questionnaire was developed by the World Health Organization and is an abbreviated version of the WHOQOL-100. The WHOQOLBREF has 26 items. Respondents respond on a five-point Likert scale. The higher the score on a given scale, the better the quality of life. The WHOQOL-BREF also contains two extra questions to be analyzed separately: - on individual and subjective rating of general quality of life,

- on subjective rating of perception of own health.

The WHOQOL-BREF was chosen for this study because it allows to assess four aspects of life which are 


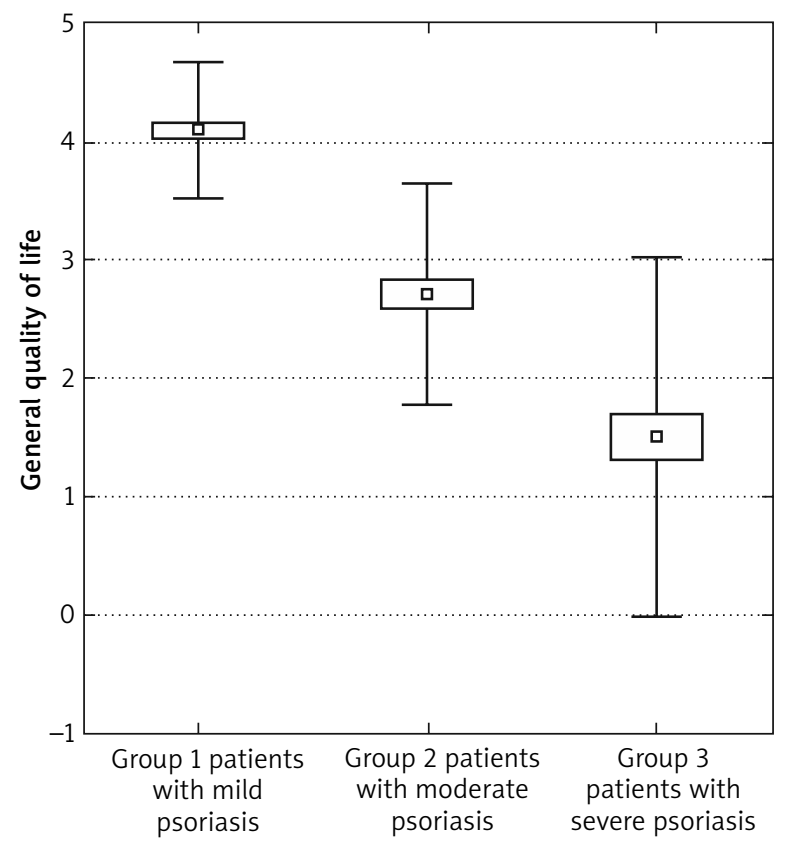

- Mean
$\square$ Mean \pm standard error
I Mean $\pm 2 \times \mathrm{SD}$

Figure 1. General quality of life in psoriatic patients in groups differing in severity of psoriatic skin changes (PASI)

very important for both healthy people and patients. These are psychological, physical, social and environmental aspects. Any abnormality in these areas can affect the patient's attitude towards the disease and treatment, especially through the need and motivation to change. Dermatological patients' expectations related to the improvement of quality of life will be likely involved in varying degrees of these four major areas of functioning.

\section{Statistical analysis}

The data were analyzed statistically using StatSoft Statistica 9.0 software. The $p \leq 0.05$ criterion of statistical significance was adopted. Since nominal, ordinal and interval scale data were analyzed, both parametric and nonparametric statistics were applied. Group differences were analyzed using ANOVA, Student- $t$ test for two independent groups and $\chi^{2}$. Correlations between variables were analyzed using the Pearson-r correlation coefficient and Spearman's rank-order coefficient.

\section{Results}

The age of onset of diagnosed psoriasis in the studied sample was between 6 and $48(M=19.3, S D=1.2)$. Duration ranged from 1 to 49 years $(M=17.4 ; S D=1.6)$. The declared duration of the last recurrence was from 1 to 72 months $(M=18.5 ; S D=2.3)$. The duration of the last remission ranged from 0 to 120 months $(M=10.4$; $\mathrm{SD}=0.8)$. The PASI score in the entire sample ranged from 0.5 to $26.6(8.86 \pm 0.8)$ (Table 1$)$.

Patients' subjective ratings of their general quality of life were also compared. It is worth mentioning that none of the studied women rated her general quality of life as very good compared with $17.65 \%$ of men. Women declared that their general quality of life was good (64.71\%) or neither good nor bad (32.35\%). Men were less likely to rate their quality of life as good (41.18\%), or neither good nor bad (17.65\%); $17.65 \%$ of men rated it as bad.

Using contingency tables and the $\chi^{2}$ test we found significant differences in general quality of life between men and women $\left(\chi^{2}=13.12 ; p \leq 0.01\right)$. Using the same test we found that patients with severe psoriatic changes had poor general quality of life $\left(\chi^{2}=10.12 ; p \leq 0.02\right)$ (Figure 1 ).

Patients rated their subjective health more poorly than their quality of life. Both male and female patients with psoriasis declared dissatisfaction with their state of health (women 38\%, men 35.29\%); $2.94 \%$ of women and $11.76 \%$ of men declared very high dissatisfaction, $26.47 \%$ of women and $17.65 \%$ of men declared moderate dissatisfaction whereas $32.35 \%$ of women and $29.41 \%$ of

Table 1. Clinical characteristics of the studied sample

\begin{tabular}{|c|c|c|c|c|c|c|c|c|c|c|c|c|}
\hline \multirow[t]{2}{*}{ Parameter } & \multicolumn{4}{|c|}{$\begin{array}{l}\text { Group } 1 \\
\text { PASI }<7\end{array}$} & \multicolumn{4}{|c|}{$\begin{array}{c}\text { Group } 2 \\
\text { PASI 7-12 }\end{array}$} & \multicolumn{4}{|c|}{$\begin{array}{l}\text { Group } 3 \\
\text { PASI > } 12\end{array}$} \\
\hline & $\bar{x}$ & $\pm \mathrm{SD}$ & Min. & Max. & $\bar{x}$ & $\pm \mathrm{SD}$ & Min. & Max. & $\bar{x}$ & $\pm S D$ & Min. & Max. \\
\hline Age at diagnosis [years] & 19.4 & 8.7 & 7 & 48 & 19.2 & 8.2 & 6 & 35 & 19.1 & 9.9 & 6 & 40 \\
\hline Duration [years] & 16.9 & 8.4 & 1 & 49 & 13.7 & 10.4 & 2 & 34 & 21.7 & 8.3 & 6 & 36 \\
\hline $\begin{array}{l}\text { Duration of the last } \\
\text { recurrence [months] }\end{array}$ & 15.9 & 3.5 & 1 & 72 & 22.0 & 5.6 & 4 & 70 & 18.1 & 3.4 & 1 & 72 \\
\hline $\begin{array}{l}\text { Duration of the last } \\
\text { remission [months] }\end{array}$ & 4.1 & 1.1 & 1 & 12 & 11.2 & 4.8 & 1 & 70 & 13.8 & 5.1 & 1 & 120 \\
\hline Number of drugs used & 1.5 & 0.1 & 1 & 4 & 1.9 & 0.3 & 1 & 5 & 2.1 & 0.3 & 1 & 5 \\
\hline
\end{tabular}

$X$-mean parameter value, SD - standard deviation, min. - minimal parameter value, max. - maximal parameter value. 
men declared that they were satisfied with the quality of their health, $5.88 \%$ of men said that they were very satisfied with the quality of their health. Using contingency tables and the $\chi^{2}$ test we found significant differences in subjective quality of health ratings between men and women $\left(\chi^{2}=10.32 ; p \leq 0.01\right)$. We also found that patients with severe psoriatic changes were dissatisfied or very dissatisfied with their health and these differences were significant, in the $\chi^{2}$ test we found significant differences in general quality of life between men and women $\left(\chi^{2}=15.59 ; p \leq 0.04\right)$.

Patients' functioning on four dimensions of quality of life (psychological, physical, environmental and social) was tested. Male and female scores for somatic, psychological and environmental functioning were compared using the $t$-Student test for two independent groups but no significant differences were found. A significant difference emerged for the fourth, social, dimension. Men declared worse quality of social life than women $(t=2.271 ; p=0.01)$.

One-way ANOVA revealed significant differences in all the analyzed dimensions of quality of life depending on severity of psoriatic changes.

Analysis of somatic quality of life included the following assessments: everyday functioning, dependency on drugs and treatment, fatigue, mobility, pain and discomfort, rest, sleep, and work capacity. Patients with mild

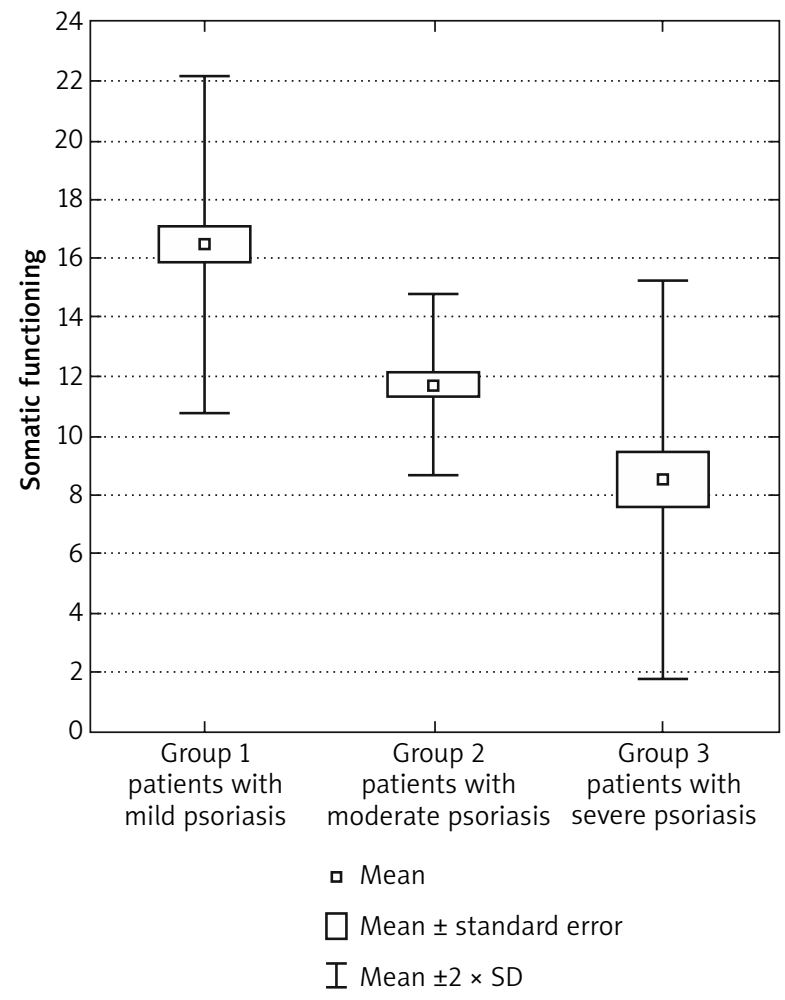

Figure 2. Somatic functioning in groups differing in severity of psoriatic skin changes (PASI) psoriatic changes had better quality of life as far as somatic functioning is concerned compared with patients with severe psoriatic changes: $\mathrm{F}(2.97)=38.96, p \leq 0.01$. Tukey's contrast test revealed significant between-group differences $(p<0.05)$ (Figure 2).

In order to assess the psychological aspect of quality of life, each patient was interviewed individually about their feelings relating to appearance, currently experienced feelings for oneself, self-esteem, spirituality, and cognitive processes (thinking, learning, memory, concentration). Patients with mild psoriatic changes functioned better on all these parameters of psychological functioning compared with patients with severe psoriatic changes: $F(2.97)=35.96, p \leq 0.01$. Tukey's contrast test revealed significant between-group differences $(p<0.05)$ (Figure 3).

To assess the social dimension of quality of life, quality of interpersonal relations (relationships, social support, sexual activity) was evaluated. Patients with mild psoriatic changes had better social functioning compared with patients with severe psoriatic changes: $F(2.97)=27.42$, $p \leq 0.01$. Tukey's contrast test revealed significant between-group differences $(p<0.05)$ (Figure 4).

To assess the environmental functioning dimension of quality of life, the following parameters were evaluated: financial resources, sense of freedom, physical and psychological safety, accessibility and quality of medical

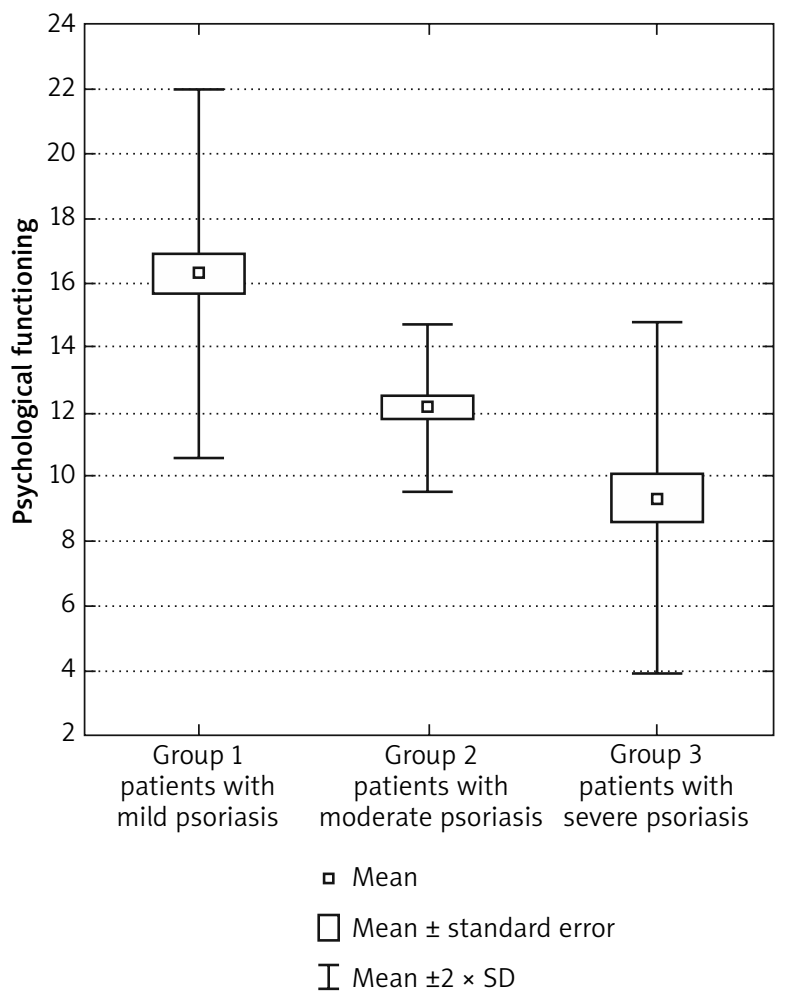

Figure 3. Psychological functioning in groups differing in severity of psoriatic skin changes (PASI) 


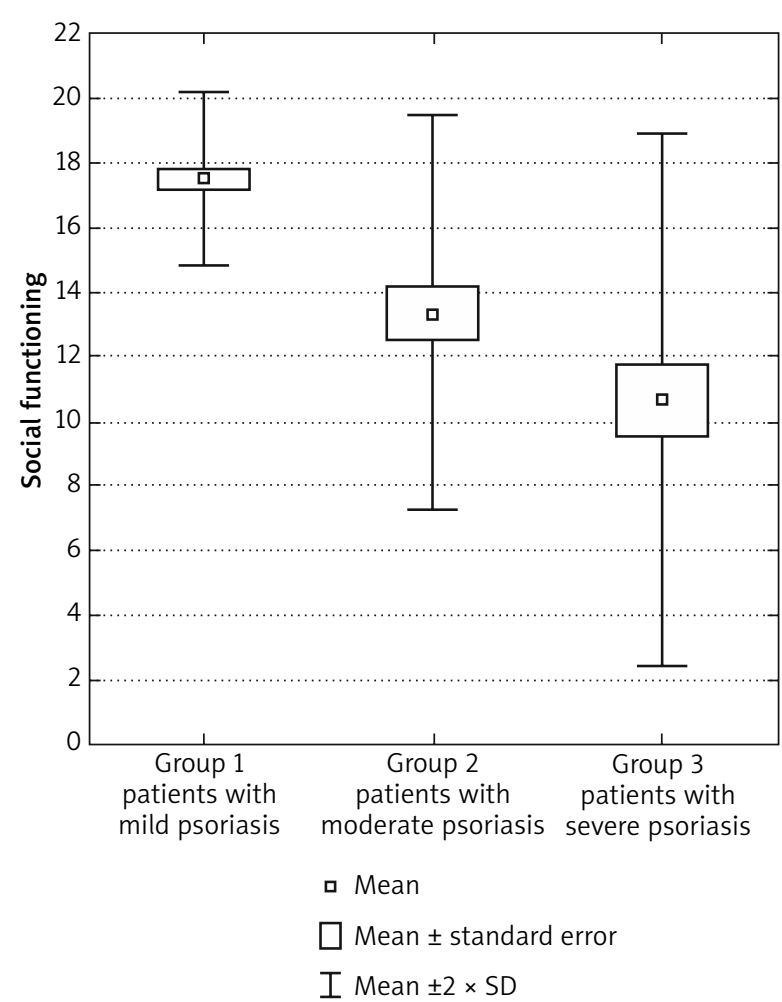

Figure 4. Social functioning in groups differing in severity of psoriatic skin changes (PASI)

care, access to new information, skills, participation in recreation and rest, and functioning at home. Patients with mild psoriatic changes functioned better environmentally compared with patients with severe psoriatic changes: $F(2.97)=38.98, p \leq 0.01$. Tukey's contrast test revealed significant between-group differences $(p<0.05)$ (Figure 5).

No significant relations $(p>0.05)$ were found between WHOQOL-BREF scores and the number of drugs used. This pattern holds for all four WHOQOL-BREF domains (correlation coefficients were low and non-significant: somatic $(r=-0.02)$, psychological $(r=0.04)$, social $(r=-0.07)$ and environmental $(r=-0.18))$. A significant relation was found between duration of the last recurrence and the social dimension of quality of life ( $r=$ 0.28; $p \leq 0.05)$. Duration of the last remission was not related to quality of life: somatic $(r=0.05)$, psychological $(r=0.15)$, social $(r=0.17)$ and environmental $(r=0.01)$.

\section{Discussion}

When someone has a chronic disease he/she finds him/herself in a specific situation, not only clinically but also psycho-socially. This may affect quality of life. Assessment of health-related quality of life is a very important supplementation of other methods of evaluation of disease severity and consequences for various dimen-

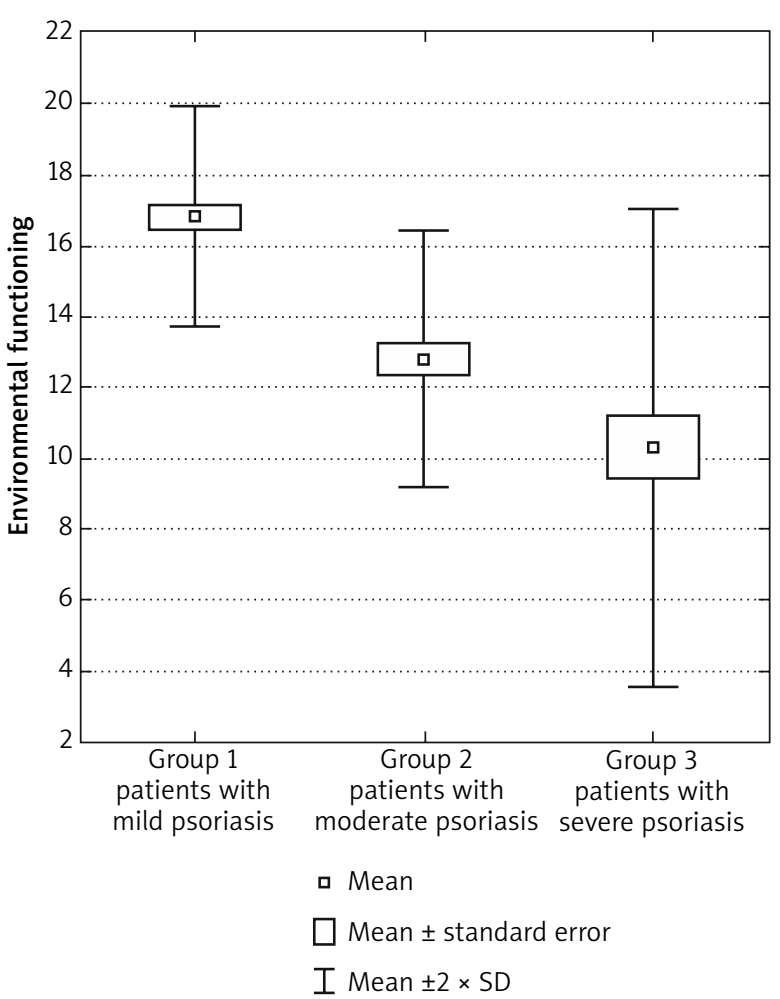

Figure 5. Environmental functioning in groups differing in severity of psoriatic skin changes (PASI)

sions of functioning. Quality of life monitoring may considerably help to objectivise treatment progress.

Patients with a dermatological condition are particularly prone to misperception of their body, and especially their skin $[6,8]$. Current research reports suggest that skin diseases may have a significant effect on functioning in all areas of life (e.g. professional, social and sexual) and on perceived quality of life $[8,18]$.

Our own research has confirmed these observations. We found that psoriatic skin changes significantly affect subjective quality of health and general quality of life. We also found that severity of psoriatic skin changes affects general quality of life (Figure 1). Patients with severe psoriatic changes were much less satisfied with life whereas patients with mild psoriatic changes (PASI $<7)$ were more satisfied. This pattern has also been reported by the European Federation of Psoriasis Associations (EUROPSO) on the basis of research conducted in Europe: $60 \%$ of patients felt their disease to be a significant problem in their everyday functioning and reduced their satisfaction with life $[5,19]$. Moons et al. [20] think that the level of satisfaction with life is the best indicator of general quality of life because it is a subjective evaluation of one's life. Patients know what aspects of life are most important for them and how affected they are by the disease. The results of the present study show that duration of recurrence correlates negatively with subjec- 
tive quality of life: the longer the recurrence of psoriatic changes, the poorer the ratings of quality of life. No such correlation was found for the number of drugs used or duration of remission. These findings are consistent with findings reported by other researchers who found differences in quality of life depending on sex [11, 21, 22].

The level of somatic functioning was significantly affected by the severity of psoriatic changes (Figure 2). The reason may lie in the way symptoms are manifested. Researchers have pointed out that psoriasis may produce various complaints: pain, burning and itching [23]. Therefore, the more severe the condition, the more physical discomfort it causes. Also, somatic complaints caused by psoriatic changes may cause difficulties in movement and general disability $[5,23]$. This in turn may lead to poorer somatic quality of life. Our findings confirm these observations. According to the literature, the negative effects of psoriasis on subjective quality of life is comparable to those observed for bronchial asthma, diabetes and coronary heart diseases [24].

We found that psoriasis has a negative effect on patients' psychological condition (Figure 3). This finding corroborates other research findings suggesting that psychological functioning may be directly related to the patient's attitude toward the disease and the need to cope with disease on a daily basis, both of which lead to negative physical self-image and negative self-esteem $[19,25,26]$. Patients with psoriasis repress their emotional conflicts and have low self-acceptance [27, 28]. Other researchers have found that the more body surface is affected, the greater the tendency to concentrate on one's health, possibly leading to poorer ratings of one's general health. Patients with psoriasis also have elevated anxiety, a state which persists even in remission [29, 30]. Patients with psoriasis are vulnerable to negative effect such as fear, dissatisfaction, anger, guilt and psychological stress. Daily chronic stress and the related loss of positive selfimage also lead to social rejection which, in turn, may exacerbate the psoriatic symptoms [31, 32]. Therefore, the level of stress which patients experience may be viewed as a prognostic factor for psycho-social dysfunction in patients with psoriasis. Reduction of emotional well-being in proportion to the severity of skin changes may lead to worse subjective quality of life and poorer psychological functioning.

Dermatological disease (psoriasis) may affect the patient's interpersonal relations, both private and professional. Psoriasis involves skin changes which may cause shame and embarrassment, leading to withdrawal from interpersonal contacts. It has frequently been reported that a considerable proportion of people still believe that psoriasis is contagious [33]. This belief often leads to negative attitudes toward patients and avoidance and, consequently, to social ostracism and stigmatization. Other researchers have found that patients with moderate to severe psoriasis are rejected by their intimate environment. Environmental rejection of this group of patients can be seen in attempts to avoid skin contact for fear of contagion. Such behaviour has a negative effect on the social functioning of patients with psoriasis $[26,32]$. We also found this effect. Patients with mild psoriasis have better interpersonal relations, more social support and are more sexually active than patients with severe psoriatic symptoms.

Psoriasis may have a negative effect on patients' professional and financial situation and also on their capacity to begin and continue studies or employment. Various writers have drawn attention to the fact that patients' quality of professional life and financial situation depend on the cost of treatment and number of days off work but do not directly depend on the severity of clinical symptoms. According to British data, nearly $60 \%$ of patients with psoriasis are on sick leave for 26 days of the year [34, 35]. Notably, some patients with psoriasis cannot do some jobs due to skin changes. An alarming $80 \%$ of patients or more report serious problems with finding a job and difficulties in interpersonal contacts at work [31, 34, 35].

\section{Conclusions}

The results of the present study show that patients with psoriasis had reduced quality of life in several areas of functioning such as general quality of life and general state of health. On the one hand, this is caused by the intra-psychic problems caused by perception of one's own skin and one's general negative self-image. On the other hand, it is caused by alarming signals from the social environment which stigmatizes the patient with psoriasis. Patients with severe psoriatic changes were much less satisfied with life than patients with moderate changes. Reduced quality of life was evident in the physical, psychological, social and environmental domains. All the relations that emerged in the study were clear and statistically significant. Both our own results and a review of the latest literature on quality of life with psoriasis suggest that, in this group of patients, basic medical interventions to reduce disease symptoms must be supplemented with individual quality of life assessment. Patients know best what aspects of life are most important for them and to what extent their illness is preventing them from gleaning satisfaction from their everyday functioning. Quality of life scales enable comprehensive assessment of the consequences of illness and are an objective indicator which can help to assess real treatment progress.

\section{Acknowledgments}

Special thanks to Professor Helena GrzegołowskaKlarkowska for the help with a professional translation. 


\section{Conflict of interest}

The authors declare no conflict of interest.

\section{References}

1. Ograńczyk A, Miniszewska M, Kępska A, et al. Itch, disease coping strategies and quality of life in psoriasis patients. Postep Derm Alergol 2014; 31: 299-304.

2. Nedoszytko B, Sokołowska-Wojdyło M, RuckemannDziurdzińska K, et al. Chemokines and cytokines network in the pathogenesis of the inflammatory skin diseases: atopic dermatitis, psoriasis and skin mastocytosis. Postep Derm Alergol 2014; 31: 84-91.

3. Maciejewska-Radomska A, Szczerkowska-Dobosz A, Rębała K, et al. Frequency of streptococcal upper respiratory tract infections and $\mathrm{HLA}-\mathrm{CW}^{\star} 06$ allele in 70 patients with guttate psoriasis from northern Poland. Postep Derm Alergol 2015; 32: $455-8$

4. Stern RS, Nijsten T, Feldman SR, et al. Psoriasis is common, carries a substantial burden even when not extensive, and is associated with widespread treatment dissatisfaction. J Invest Dermatol Sympos Proceed 2004; 9: 136-9.

5. Basińska MA, Drozdowska M. Emotional intelligence as an indicator of satisfaction with life of patients with psoriasis. Postep Derm Alergol 2013; 30: 365-72.

6. Jankowiak B, Sekmistrz S, Kowalewska B, et al. Satisfaction with life in a group of psoriasis patients. Postep Derm Alergol 2013; 30: 85-90.

7. Reich A, Welz-Kubia K, Rams $Ł$. Apprehension of the disease by patients suffering from psoriasis. Postep Derm Alergol 2014; 31: 289-93.

8. de Korte J, Sprangers MA, Mombers FM, et al. Quality of life in patients with psoriasis: a systematic literature review. J Investig Dermatol Symp Proc 2004; 9: 140-7.

9. Owczarek K. The quality of life concept. Acta Neuropsychologica 2010; 8: 207-13.

10. Janowski K, Steuden S, Bogaczewicz J. Clinical and psychological characteristics of patients with psoriasis reporting various frequencies of pruritus. Int J Dermatol 2014; 53: 820-9.

11. Miękoś-Zydek B, Ryglewska-Cho A, Lassota-Falczewska M, et al. Jakość życia pacjentów z łuszczycą. Postep Derm Alergol 2006; 23: 273-7.

12. Nash AS, McAteer H, Schofield J, et al. Psoriasis today: experiences of healthcare and impact on quality of life in a major UK cohort. Prim Health Care Res Dev 2014; 5: 1-9.

13. Kanikowska A, Pawlaczyk M. Narzędzia wykorzystywane do oceny jakości życia chorych na łuszczycę. Dermatol Klin 2006; 8: 132-6.

14. Pietrzak A, Janowski K, Lechowska-Mazur I, et al. Łuszczyca jako przewlekła choroba skóry w kontekście psychologicznym. Nowa Medycyna 2006; 1: 14-9.

15. Jaworski M. Relationship between health behaviors and quality of live on the one hand and satisfaction with health conditions on the other hand in patients with psoriasis. Our Dermatol Online 2013; 4: 453-7.

16. Louden BA, Pearce DJ, Lang W, et al. A Simplified Psoriasis Area Severity Index (SPASI) for rating psoriasis severity in clinic patients. Dermatol Online J 2004; 10: 7.

17. Schmitt J, Wozel G. The psoriasis area and severity index is the adequate criterion to define severity in chronic plaquetype psoriasis. Dermatology 2005; 210: 194-9.

18. Ermertcan TA, Temeltaş G, Deveci A, et al. Sexual dysfunction in patients with psoriasis. J Dermatol 2006; 33: 772-8.
19. Mease PJ, Menter MA. Quality of life issues in psoriasis and psoriatic arthritis: outcome measures and therapies from a dermatological perspective. J Am Acad Dermatol 2006; 54: 685-704.

20. Moons P, Budts W, De Geest S. Critique on the conceptualisation of quality of life: a review and evaluation of different conceptual approaches. Int J Nurs Sudies 2006; 43: 891-901.

21. Wielowieyska-Szybińska D, Wojas-Pelc A. Psoriasis: course of disease and treatment. Postep Derm Alergol 2012; 29: 118-22.

22. Rosen DF, Mussani F, Chandran V, et al. Patients with psoriatic arthritis have worse quality of life than those with psoriasis alone. Rheumatology 2012; 51: 571-6.

23. Ljosaa TM, Rustoen T, Mork C, et al. Skin pain and discomfort in psoriasis: an exploratory study of symptom prevalence and characteristics. Acta Derm Venereol 2010; 90: 39-45.

24. Finlay AY, Coles EC. The effect of severe psoriasis on the quality of life of 369 patients. Br J Dermatol 1995; 132: 23644.

25. Basińska MA, Woźniewicz A. The relation between type D personality and the clinical condition of patients suffering from psoriasis. Postep Derm Alergol 2013; 30: 381-7.

26. Fortune D, Richards H, Griffiths C. Psychologic factors in psoriasis: consequences, mechanisms, and interventions. Dermatol Clin 2005; 23: 681-94.

27. Kostyra M, Tabała K, Kocur J. Illness acceptance degree versus intensity of psychopathological symptoms in patients with psoriasis. Postep Derm Alergol 2013; 30: 134-9.

28. Krueger G, Koo J, Lebwohl M, et al. The impact of psoriasis on quality of life: results of a 1998 National Psoriasis Foundation patient-membership survey. Arch Dermatol 2001; 137: 280-4.

29. Duran V, Jovnovic M. The effect of psoriasis. Med Pregl 1993; 46: $120-6$.

30. Harvima T, Viinamaki H, Naukkarinen A, et al. Association of cutaneous mast cells and sensory nerves with psychic stress in psoriasis. Psychother Psychosom 1993; 60: 168-75.

31. Choi J, Koo JYM. Quality of life issues in psoriasis. J Am Acad Dermatol 2003; 49: 57-61.

32. Gupta MA, Gupta AK. Quality of life of psoriasis patients. J Eur Acad Dermatol Venereol 2000; 14: 241-2.

33. Javitz HS, Ward MM, Farber E, et al. The direct cost of care for psoriasis and psoriatic arthritis in the United States. J Am Acad Dermatol 2002; 46: 850-60.

34. Horn E, Fox KM, Patel V, et al. Association of patient-reported psoriasis severity with income and employment. J Am Acad Dermatol 2007; 57: 963-71.

35. Skevington SM, Bradshaw J, Hepplewhite A, et al. How does psoriasis affect quality of life? Assessing an Ingram-regimen outpatient program and validating the WHOQOL-100. Br J Dermatol 2006; 154: 680-91. 